\title{
Impacts of Snowy Weather Conditions on Expressway Traffic Flow Characteristics
}

\author{
Jiancheng Weng, Lili Liu, and Jian Rong \\ Beijing Key Laboratory of Traffic Engineering, Beijing University of Technology, No. 100, Pingleyuan, \\ Chaoyang District, Beijing 100124, China \\ Correspondence should be addressed to Jiancheng Weng; youthweng@bjut.edu.cn
}

Received 13 September 2012; Revised 11 January 2013; Accepted 11 January 2013

Academic Editor: Wuhong Wang

Copyright (C) 2013 Jiancheng Weng et al. This is an open access article distributed under the Creative Commons Attribution License, which permits unrestricted use, distribution, and reproduction in any medium, provided the original work is properly cited.

\begin{abstract}
Snowy weather will significantly degrade expressway operations, reduce service levels, and increase driving difficulty. Furthermore, the impact of snow varies in different types of roads, diverse cities, and snow densities due to different driving behavior. Traffic flow parameters are essential to decide what should be appropriate for weather-related traffic management and control strategies. This paper takes Beijing as a case study and analyzes traffic flow data collected by detectors in expressways. By comparing the performance of traffic flow under normal and snowy weather conditions, this paper quantitatively describes the impact of adverse weather on expressway volume and average speeds. Results indicate that average speeds on the Beijing expressway under heavy snow conditions decrease by $10-20 \mathrm{~km} / \mathrm{h}$ when compared to those under normal weather conditions, the vehicle headway generally increases by $2-4$ seconds, and the road capacity drops by about $33 \%$. This paper also develops a specific expressway traffic parameter reduction model which proposes reduction coefficients of expressway volumes and speeds under various snow density conditions in Beijing. The conclusions paper provide effective foundational parameters for urban expressway controls and traffic management under snow conditions.
\end{abstract}

\section{Introduction}

The presence of fog, dust, rain, snow, or smoke in the atmosphere makes a driver's task more difficult. Since the middle of the twentieth century [1], it has been recognized that weather conditions have special influence on the road network operation due to the various behaviors of drivers under different weather conditions. Since the 1970s, several studies have focused on quantitative impact evaluations of the transportation system performance under adverse weather conditions in the USA [2-4]. They have confirmed that adverse weather conditions can significantly reduce the operating speed and thus the capacity in a given road segment [5]. However, few studies on road conditions and driver's behavior during inclement weather have been conducted in China. Due to the insufficient traffic performance analysis and traffic flow characteristic studies of traffic behavior in inclement weather in China, the implementation of traffic management measures, traffic control strategies, and traffic designs for inclement weather conditions has usually been set and adjusted based only on a personal experience. This approach is quite impractical because it requires a traffic operator to manually change the settings in the field which deeply affects the reliability and efficiency of the traffic system. Specifically, the research on the impact of adverse weather in China has mainly focused on freeway management and traffic safety guarantees [6-9]. Adverse weather undoubtedly makes the driving operation more difficult, but it is still unclear how much and what changes should be made under various inclement weather conditions' even though a previous research based on empirical methods $[10,11]$ and simulation methods [12-14] has revealed that there is a substantial impact on driving in adverse weather.

Of all the adverse weather conditions, snow has the most significant effect on the driving behavior and vehicle performance because of the dual influence of road surfaces and visibility problems [15]. The snow scatters lights and creates a great amount of visual noise in a driver's visual field. In addition, if the snow is heavy enough, it covers the road surface, obscuring lane markings and road signs designed to 
aid the driver. If the temperature is still low in the next day, the road surface freezes which then leads to a new threat to vehicles and traffic flow.

Several studies have examined the impact of snow and ice conditions specifically. McBride [2] evaluated the economic impact of highway controls and operation under snow and ice conditions and estimated the extra fuel consumption and the additional travel delay. Ibrahim and Hall [16] processed the traffic flow data collected from a freeway in Ontario, Canada, by using multivariable regression analysis methods and found that there was a $3 \%-5 \%$ speed reduction with light snow and a $30 \%-40 \%$ reduction in travel speeds with heavy snow. The Minnesota Department of Transportation also conducted a study based on data collected from a busy metropolitan freeway, highway 36, during rush hours between 3:00 and 8:00 PM on several weekdays under different weather conditions [11]. Their analysis showed that speeds dropped from 44 to $26 \mathrm{mph}(40 \%)$, saturation flows decreased from 1800 to $1600 \mathrm{v} / \mathrm{l} / \mathrm{h}(11 \%)$, and the start-up delays increased from 2 to 3 seconds.

Ren [17] also analyzed road sections and intersection run characteristics under a single snowy weather event and calculated the reduction percentages of road capacity, traffic volume, and travel speed at different intensity levels of snow. However, his conclusions were not universal and were inapplicable for other cities and other weather conditions.

Other authors have suggested potential solutions to help traffic flow during difficult weather conditions. Hu [14] discussed the impact of snowy weather on signal timing and evaluated the performance of intersection signals under icy and snowy weather conditions using a traffic simulation approach. Their simulation results indicated that a weatherresponsive signal scheme can enhance traffic conditions, decrease travel delays, and raise travel speeds. Al-Kaisy and Freedman [18] presented a systematic investigation into the effects of adverse weather on signal operation and developed a set of recommended guidelines that relate weather conditions to operational impacts and potential benefits of weather-responsive signal timing.

The research also shows that drivers experience and behavior have an obvious influence on the traffic flow characteristics [19]. In most northern states in the USA, serious adverse weathers like snow storms occur frequently, so drivers are familiar with the conditions and have the experience driving under these adverse weathers, so they modify their driving habits accordingly. These modifications usually involve reducing speed and keeping greater distances between vehicles. Boyce's study illustrates that there are different influences and principles of snow's impact in different cities.

Some studies have also reported that the impact of weather conditions on traffic flow relationships and parameters is different depending on the road type. Chin et al. [20] established a traffic performance decrease table of various classes of roads under six different inclement weather conditions including light rain, heavy rain, light snow, heavy snow, fog, and ice. They used loop detector data gathered from different regions of the USA. From these data, it is clear that not all weather conditions affect the traffic and driver's behavior equally.

In conclusion, a substantial amount of research has been conducted in other countries, providing models of significant reductive models in terms of capacity, travel, and signal timing; in contrast, studies on the impact of snowy weather in different cities and different road networks are inadequate and not systemic in China, and even less research has integrated traffic data supports. Therefore, few studies can respond to the questions of how to identify and evaluate traffic flow characteristics in snowy weather in Beijing and which countermeasures and traffic management strategies should be implemented such as access signal adjustments, expressways merge control, and lane closures.

The current study was initiated in response to this need. Specifically, this study attempted to analyze the traffic performance of expressways under different weather conditions in Beijing using the detector data. The results are revealed in three aspects including travel speed, traffic volume, and the saturation flow rate. Furthermore, a specific expressway traffic parameter reductive model under adverse weather conditions of various snow volume levels was developed. Finally, the main conclusions derived from the study are summarized.

\section{Traffic Flow Data}

The traffic flow data used in this study were collected from the microwave detectors which are installed on the expressways in Beijing. The expressway plays a significant role in the urban road network operation and accounts for more than $25 \%$ of the commuter travel mileages in Beijing. The time period of data collection was during the day (from 6:00 AM to 10:00 PM) on the snowy day with different snowfalls and the subsequent day. In order to enhance the data credibility, videotaped data were also collected over a period of several hours to calibrate the fixed detectors.

The time interval of data collection was 2 minutes, and the main fields of traffic flow data including travel speed, traffic volume, and occupancy were recorded in the database. The data were combined to analyze the traffic performance of road sections. The main fields of detector data are shown in Table 1.

A data before the process was implemented to eliminate data errors and faults and to improve the traffic data reliability since error data or lost data can result from mechanical errors of the detectors. The procedures including data filtering, data recovery, and data denoising are required to gain higherquality data. Based on the processed data, the macroscopic indexes of traffic volume, travel speed, and density can be estimated and used to describe the basic characteristics of traffic flow under different weather conditions.

\section{Speed Analyses}

3.1. General Characteristics of Travel Speed under Snow Conditions. Traffic volume on expressways shows an obvious decline under heavy snowy weather conditions compared to 
TABLE 1: Main fields of microwave detector data in Beijing.

\begin{tabular}{|c|c|c|c|c|c|}
\hline Date & Time ID & Detector ID & Detected speed $(\mathrm{km} / \mathrm{h})$ & Occupancy & Traffic flow (veh.) \\
\hline $2009-12-27$ & 655 & HI7052c & 33.6 & 2 & 14 \\
\hline $2009-12-27$ & 655 & HI9141d & 16.8 & 7 & 24 \\
\hline $2009-12-27$ & 655 & HI9073d & 39.8 & 3 & 21 \\
\hline $2009-12-27$ & 656 & HI7052c & 23.1 & 4 & 27 \\
\hline
\end{tabular}

those under normal weather, and even the spot speed has a little increase [21]. To illustrate the general characteristics of traffic flow and speed under adverse weather conditions, the data was collected on January 3, 2010 with heavy snow (snow precipitation is greater than $5.0 \mathrm{~mm}$ ) and December 27, 2009 with normal weather. The traffic flow data of each direction in twelve different points which located in the four orientations of the expressways including the second, the third, and the forth ring road in Beijing were analyzed. The observation time included multiple periods and was not restricted to the peak periods because of the unpredictable nature of snowfall intensity. The three-time periods were compared including the morning peak hours, the evening peak hours, and the offpeak hours.

The results are shown in Table 2. The average travel speed was the average value of the multiple groups' detected speed, and the section traffic volume was the average hourly observed volume during the specified time periods. From the result, it can be concluded that there was about 65\% drop in traffic volume on the Beijing expressway under heavy snow conditions, but the travel speed was almost the same as the normal weather conditions due to the great drop of travel demand. The reason may be that there was a new balance between the decreased travel demand and deteriorated road supply condition.

Traffic volume and snow are the primary factors which affect the average velocity of the expressway on a snowy day because the road condition, geometric design, and time of day are all the same in different days. The heavy snowy day observed in this study was Sunday, so people had less rigid travel demands such as commuting. In addition, longdistance travel demand was likely canceled due to the heavy snow, and people only attempted to travel near their homes. Therefore, the traffic volume experienced a steep drop on the expressway from $65 \%$ to $72 \%$ because of the decreased long-distance travel. Thus, there was a large-scale drop in traffic volume, and mutual disturbances between vehicles were reduced, which even led to an increase in the peak hour and slight speed drop in off-peak hour on the identical road sections.

During off-peak hours, vehicles on the expressway also had high freedom to drive under the normal weather; consequently, the snow factor played a leading role in the speed change in snowy weather and caused a $10 \%$ speed reduction. In the evening peak hours, the traffic volume dropped over $70 \%$ resulting from the travel demand reduction. This alleviated the high-road pressure during the evening peak hours compared to normal weather conditions, which even enabled the average speed of the expressway to increase by $20 \%$.

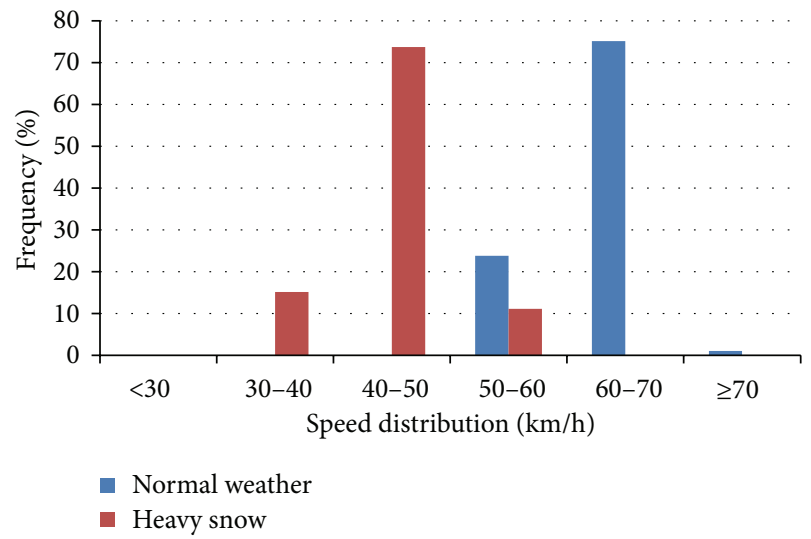

FIGURE 1: Spot speed distribution difference under the same traffic volume levels.

3.2. Travel Speed under Same Traffic Volume Levels. This study selected certain road sections which typically have the same traffic volume levels and similar geometric design to analyze the traffic data collected separately during normal weather and snowy weather conditions. Hence, after the velocity distribution analysis based on the data which was collected on January 3, 2010 with heavy snow and December 27, 2009 with normal weather during the time period of 6:00 AM to 10:00 PM, travel speed reductions caused by the heavy snow were revealed. The influence of various weather conditions on speed distribution is summarized in Table 3.

As can be seen from Table 3 and Figure 1, the spot speed distributions under the same traffic volume levels have obvious differences due to the impact of heavy snow. The average speeds generally drop by $10-20 \mathrm{~km} / \mathrm{h}$ with heavy snow. During normal weather, the speed mainly is distributed in the range of $60-70 \mathrm{~km} / \mathrm{h}$, which accounts for about $70 \%$ in all collected samples. Under heavy snow conditions, the speed was mainly distributed in the range of $40-50 \mathrm{~km} / \mathrm{h}$. This decreased speed was caused by the road conditions and driver's behaviors when there was heavy snow. The road surface and markings were obscured by the snow, and the visual fields were limited. Accordingly, drivers subconsciously decreased their speeds as they became used to the surrounding environment. Thus, the peak values of speed under the snow conditions were much lower than normal.

\section{Speed-Volume Relationship Analysis}

The observed traffic volume on expressways changes along with the travel demand and the road network operation level. 
TABLE 2: Traffic flow characteristics of expressway under various weather conditions.

\begin{tabular}{|c|c|c|c|c|c|c|}
\hline \multirow{2}{*}{$\begin{array}{l}\text { Time period } \\
\text { Weather condition }\end{array}$} & \multicolumn{2}{|c|}{ Morning peak } & \multicolumn{2}{|c|}{ Evening peak } & \multicolumn{2}{|c|}{ Off-peak } \\
\hline & Heavy snow & Normal weather & Heavy snow & Normal weather & Heavy snow & Normal weather \\
\hline Average speed $(\mathrm{km} / \mathrm{h})$ & 56.60 & 54.96 & 59.84 & 46.05 & 64.36 & 71.71 \\
\hline Volume per hour (veh./h) & 1632 & 4722 & 1378 & 4952 & 832 & 2751 \\
\hline Speed change on heavy snowy day (\%) & \multicolumn{2}{|r|}{+2.98} & \multicolumn{2}{|c|}{+29.95} & \multicolumn{2}{|c|}{-10.26} \\
\hline Volume reduction $(\%)$ & \multicolumn{2}{|r|}{65.44} & \multicolumn{2}{|c|}{72.17} & \multicolumn{2}{|c|}{69.76} \\
\hline
\end{tabular}

TABLE 3: Spot speed distribution in certain expressway section.

\begin{tabular}{lcccccc}
\hline & Spot speed $(\mathrm{km} / \mathrm{h})$ & $<30$ & $30-40$ & $40-50$ & $50-60$ & $60-70$ \\
Distribution & Normal weather & 0 & 0 & 0 & 23.81 & 75.15 \\
Frequency (\%) & Heavy snow & 0 & 15.14 & 73.72 & 11.14 & 0 \\
\hline
\end{tabular}

The relationship between the observed flow rate and the velocity can reveal the characteristics of expressways under specific weather conditions and the road environment. The parameters including free-flow speed and saturation flow are usually used to reflect the difference. The research illustrates these data in the speed-flow rate scatter diagram by using the traffic flow data collected under normal weather and heavy snowy weather conditions (see Figure 2) and also conducted the preliminary regression fitting.

It can be clearly seen from the scatter diagram in Figure 2 that the maximum hour flow rate in the normal weather situation is much larger than the one in the heavy snow condition, and the average free-flow speed under heavy snow is about $20 \mathrm{~km} / \mathrm{h}$ lower compared to those under normal weather. The vertex of the flow rate-the velocity curve corresponding to the flow rate-can be theoretically regarded as the saturation flow which is also the capacity of a single lane $[22,23]$. As shown in the scatter diagram, the capacity of a single lane on the expressway is approximately $1800 \mathrm{vph}$ in normal weather, but the snow caused the curve to show inward side displacement, and the single lane capacity is about $1200 \mathrm{vph}$, which is a remarkable $33 \%$ drop. It also means that the saturated vehicle headway in heavy snow is much higher than that of normal weather. The obvious differences are caused by the traffic volume decrease, and the drivers' behavior changes under snow conditions. Because the braking performance of vehicles on the slippery road surface shows a noticeable decline during heavy snow, the drivers tend to take action to modify speeds and keep greater distances between vehicles.

The horizontal line passes the vertex of the relationship curve dividing the curve into two parts with an upper half curve and a lower half curve. Thus, the corresponding speed of this line is defined as the speed at capacity [22]. The traffic flow among the region encircled by the level line and the upper half curve is a steady flow, and the vehicles can drive at a steady and smooth speed. Conversely, the region encircled by the level line and the lower half curve is the force flow area, and the traffic flow in this region has to move at a low speed near the congestion condition.

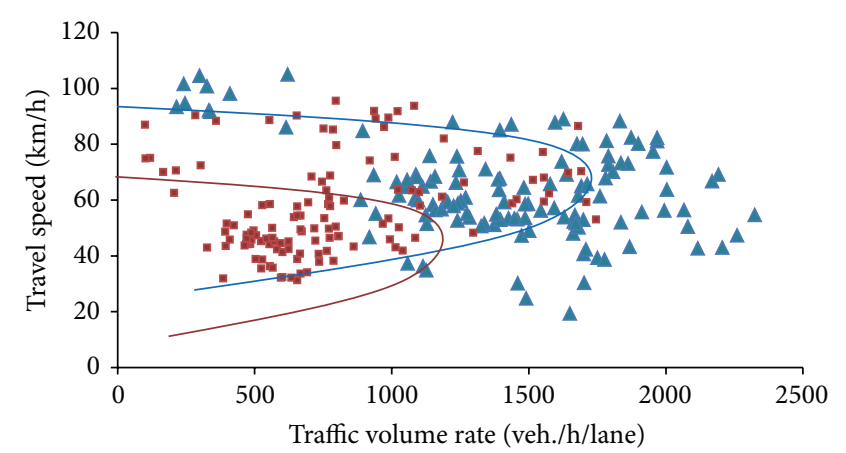

- Normal weather

- Adverse weather

FIGURE 2: Observed speed-flow rate scatter diagram under various weathers. Note: the two regression lines in the figure are just the sketch fitting.

As seen in Figure 2, the majority of the data points are distributed in the upper part under normal weather, and the vehicles can drive at a higher speed than the speed at capacity. However, the majority of the data points are distributed on both sides of the critical speed in the heavy snow situation, and partial vehicles were influenced by the snow and were forced to drive at a lower speed.

\section{Reduction Coefficients of Traffic Flow under Various Snow Densities}

From the former analysis, it can be concluded that snow has an obvious impact on traffic flow parameters on the expressway and often leads to various degrees of speed reductions. However, there are different reduction percentages under different snow densities. Consequently, besides the heavy snowy day (January 3, 2010) and normal weather day (December 27, 2009), we also collected data from the same detectors on November 10, 2009 with medium snow (snow precipitation is about $3.0 \mathrm{~mm}$ ) and November 17, 2009 with 
TABLE 4: Reduction coefficients of traffic flow parameters under various snow densities.

\begin{tabular}{lccccc}
\hline \multirow{2}{*}{ Snow density } & & Heavy snowy day & $\begin{array}{c}\text { Day after heavy } \\
\text { snow }\end{array}$ & $\begin{array}{c}\text { Moderate snowy } \\
\text { day }\end{array}$ & Light snowy day \\
\hline Average & Volume & 42.70 & 39.05 & 13.95 & 2.11 \\
Reduction percentage (\%) & Speed & 28.01 & 5.07 & 6.60 & 1.77 \\
\hline
\end{tabular}

normal weather as well as on January 9, 2010 with light snow (snow precipitation is about $0.7 \mathrm{~mm}$ ) and January 16, 2010 with normal weather. The study analyzed the detector data collected from the expressway on several snow days with various snow densities, and the reduction coefficients of traffic flow parameters under light snow, medium snow, and heavy snow were derived from the analysis.

\subsection{Reduction Coefficient under Heavy Snow}

5.1.1. The Snow Day. Beijing experienced a snowstorm day on January 3, 2010, and the thickness of snow exceeded $20 \mathrm{~cm}$. The data on December 27, 2009 with normal weather was selected to compare with the data on the snowy day. The same volume level data on both days were selected to analyze the spot speed reductions.

Because the observed snowy day was on the weekend, rigid travel demand was small; thus, the entire day's travel demand substantially dropped as a result of the heavy snow, but there were different degrees of reductions in different locations. The flow rates in the partial data set had a decrease of $40 \%-60 \%$ which indicated that these expressway road sections had a high proportion of elastic travel demand, and the road section users were highly sensitive to the weather conditions. On the other hand, the other partial observation points had a volume decline of about $15 \%$ 25\% which means that the travel demand on these expressway road sections had strong rigidity. The mean traffic volume reduction was about $40 \%$, which is a little smaller than the former road sections

In addition, the researcher chose multiple groups of data under similar traffic flow levels on both days to compare the speed drops under the heavy snow conditions using contrast analysis. The data analysis indicated the following conclusions: (1) under the different traffic flow levels, the degree of speed reductions was different; (2) the lower the volume level, the greater the speed reduction; (3) the speeds declined at a percentage between $15 \%$ and $40 \%$, and the average speed drop under heavy snow was about $28 \%$.

5.1.2. The Subsequent Day after Snow. The data collected on January 4, 2010 was selected to illustrate the traffic performance in the next day after heavy snow. Some roads were icy, and the road conditions had worsened further on that day. As a result of the working day, the majority of travelers had rigid travel demands to go to work, but more people are attempt to travel with public transit; therefore, the traffic volume reduction was slightly smaller than the weekend at $20 \%-50 \%$. There were almost no obvious differences during the peak hours and the off-peak hours with a volume reduction for both at about $40 \%$. At the same time, the driving speed did not obviously drop because the volume on the expressway showed a noticeable decline compared to the workday in normal weather. This indicates that the traffic controls and the policies have effectively guaranteed the road network movement and maintained an acceptable service level.

Based on the former data analysis, we can assume that the traffic flow characteristics on the heavy snowy day have a remarkable impact, but traffic conditions of the expressway on the subsequent day are not obviously worse with the help of traffic management countermeasures and the implementation of the adjustable work time policy. The work time is flexible as suggested by municipality, and the pupils are suspended from school for safety, and these countermeasures objectivity reduced the travel demand on that day. The average speed on the heavy snowy day dropped about $28 \%$, and the speed on the next day only had an approximate 5\% reduction. This indicates that Beijing has suitable traffic controls, and the organization measures have brought about a positive outcome to alleviate the impact of heavy snow.

5.2. Reduction Coefficient under Lighter Snow. To reveal the different influences on expressway traffic flow, data collected on days with various snow densities between November, 2009 and January, 2010 were also analyzed in this paper. Based on the data analysis, the results are concluded as follows: (1) under heavy snow (precipitation is greater than $5.0 \mathrm{~mm}$ ), drivers will reduce their travel demand, and the snow coverage and visibility will influence traffic flow and expressway operations and often lead to an obvious reduction in both traffic volume and travel speed; (2) with moderate snowfall (precipitation is greater than $2.5 \mathrm{~mm}$ and smaller than $5.0 \mathrm{~mm}$ ) and light snow (precipitation is smaller than $2.5 \mathrm{~mm}$ ), the impact of the snow on expressway traffic flow is small, and the volume and the speed only have slight reductions; (3) Table 4 shows the reduction coefficients of traffic flow parameters under various snow densities.

In conclusion, the reduction coefficients of traffic flow parameters under various snow densities in Beijing can be recommended. The volume reductions on the expressways separately are $40 \%, 15 \%$, and $5 \%$ under heavy snow, moderate snow, and light snow, respectively, and the average speed of expressway reductions is separately $25 \%, 8 \%$, and $0 \%$ under the heavy snow, moderate snow, and light snow, respectively.

\section{Conclusions}

Based on comparisons between traffic flow data and parameters under various snow intensities on snowy days and normal weather days in different snowfall precipitation day, the paper recorded the reductions of traffic flow parameters 
on the expressway. The results indicate that the average speeds on the expressway under heavy snow conditions have a $10-20 \mathrm{~km} / \mathrm{h}$ decrease when compared to those under normal weather conditions, the saturated vehicle headway generally increases, and the road capacity drops about $33 \%$. Furthermore, a specific expressway traffic parameter reduction model under various snow volume levels was developed. It summarized the reduction coefficients of expressway volumes and speeds at same volume levels under various snow densities in Beijing. The paper's conclusions provide an effective support and reference for urban expressway controls and traffic management strategies to reduce speeds and alleviate congestion during snow conditions.

Nevertheless, this paper is mainly based on the detector data, and the multisource traffic data including video data and loop detectors data can be introduced to improve the accuracy of the reduction model in the future research, or under other different adverse weather conditions, and more microscopic characteristics of traffic flow model can be revealed by using the multisource traffic data.

\section{Acknowledgments}

This paper was supported in part by the National Natural Science Foundation of China with no. 51108013 and the Ministry of Industry and Information Technology of China under the Major Program of National Science and Technology with no. 2013ZX01045003-002. The authors would like to show great appreciation for these supports.

\section{References}

[1] J. C. Tanner, "Effect of weather on traffic flow," Nature, vol. 169, no. 4290 , p. $107,1952$.

[2] J. C. McBride, "Economic impact of highway snow and ice control," Final Report, Federal Highway Administration Report FHWA-RD-77-95, Washington, DC, USA, 1977.

[3] Kleitsch and Cleveland, "The effect of rainfall on freeway capacity,” Tech. Rep. HSRI TrS-6, Highway Safety Research Institute, University of Michigan, Ann Arbor, Mich, USA, 1971.

[4] E. R. Jones and M. E. Goolsby, "Effect of rain on freeway capacity," Research Record 14-23, Texas Transportation Institute, Texas A\&M University, College Station, Tex, USA, 1969.

[5] Highway Capacity Manual Fourth Edition (HCM, 2000), Transportation Research Board of the National Academies, Washington, DC, USA, 2000.

[6] H. Y. Wang, Q. J. Xiang, J. Lu, and Y. W. Ren, "Influence of adverse weather on vehicle trip at freeway," Journal of Traffic and Transportation Engineering, vol. 5, no. 1, pp. 124-126, 2005.

[7] K. Y. Dong and B. C. Lu, "Influences of bad weather to movements of vehicles," Journal of Chongqing Jiaotong University, vol. 8, no. 6, pp. 24-26, 2008.

[8] Q. Li and F. S. Liu, "A moderate expressway vehicle flow control under adverse weather condition," Shandong Transportation Technology, vol. 3, pp. 9-11, 2009.

[9] W. H. Wang, F. G. Hou, H. C. Tan, and H. Bubb, "A framework for function allocations in intelligent driver interface design for comfort and safety," International Journal of Computational Intelligence Systems, vol. 3, no. 5, pp. 531-541, 2010.
[10] "Empirical studies on traffic flow in inclement weather," Federal Highway Administration Report FHWA HOP-07-073, Cambridge Systematics, Inc, and Virginia Tech Transportation Institute, 2006.

[11] P. J. Maki, "Adverse weather traffic signal timing," in Proceedings of the 69th Annual Meeting of the Institute of Transportation Engineers, Las Vegas, Nev, USA, 1999.

[12] H. C. Lieu and S. M. Lin, "Benefit assessment of implementing weather-specific signal timing plans by using CORSIM," Transportation Research Record, no. 1867, pp. 202-209, 2004.

[13] L. Zhang, P. Holm, and J. Colyar, "Identifying and assessing key weather-related parameters and their impacts on traffic operations using simulation," Federal Highway Administration Report FHWA-HRT-04-131, 2004.

[14] M. W. Hu, "Impact analysis of inclement weather on traffic signal timing," Transportation Standardization, vol.169, pp. 156160, 2007.

[15] W. Wang, Y. Mao, J. Jin et al., "Driver's various information process and multi-ruled decision-making mechanism: A fundamental of intelligent driving shaping model," International Journal of Computational Intelligence Systems, vol. 4, no. 3, pp. 297-305, 2011.

[16] A. T. Ibrahim and F. L. Hall, "Effect of adverse weather conditions on speed-flow-occupancy relationships," Transportation Research Record, no. 1457, pp. 184-191, 1994.

[17] Y. Y. Ren, Study on the Characteristics of Traffic Stream and Management Countermeasure at Urban Road under the Condition [M.S. thesis], Jinlin University, Jilin, China, 2008.

[18] A. Al-Kaisy and Z. Freedman, "Weather-responsive signal timing: practical guidelines," Transportation Research Record, no. 1978, pp. 49-60, 2006.

[19] P. R. Boyce, Lighting For Driving: Roads, Vehicles, Signs, and Signals, CRC Press, Boca Raton, Fla, USA, 2009.

[20] S. M. Chin, O. Franzese, D. L. Greene, H. L. Hwang, and R. C. Gibson, "Temporary loss of highway capacity and impact on performance: phase 2," Tech. Rep. ORNL/TM-2004/209, Oak Ridge National Laboratory, 2004.

[21] L. Y. He, Traffic Congestion Issues of Urban Arterial Road under Inclement Weather and Countermeasure [M.S. thesis], Central South University, Changsha, China, 2009.

[22] F. T. Ren, X. M. Liu, and J. Rong, Traffic Engineering, Communications Press, Beijing, China, 2008.

[23] X. Q. Zhang, S. An, and H. F. Sheng, "Discrete dynamic road network capacity under adverse weather," Journal of Harbin Institute of Technology, vol. 41, no. 7, pp. 85-88, 2009. 


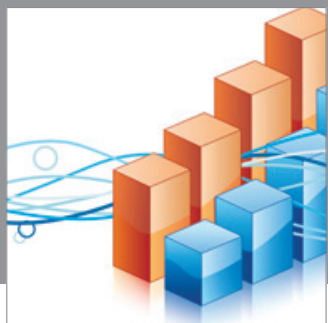

Advances in

Operations Research

mansans

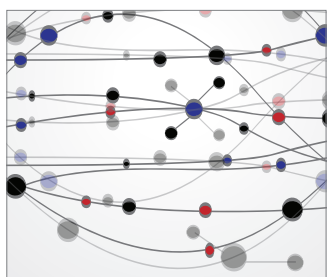

The Scientific World Journal
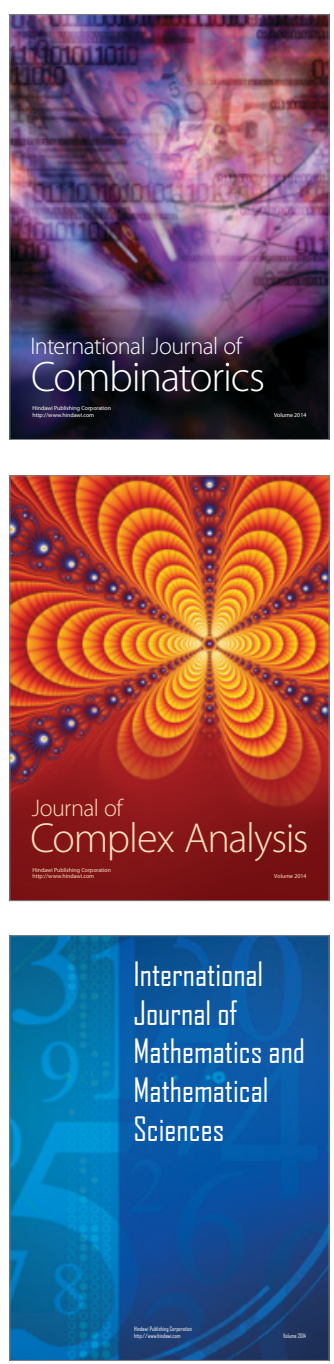
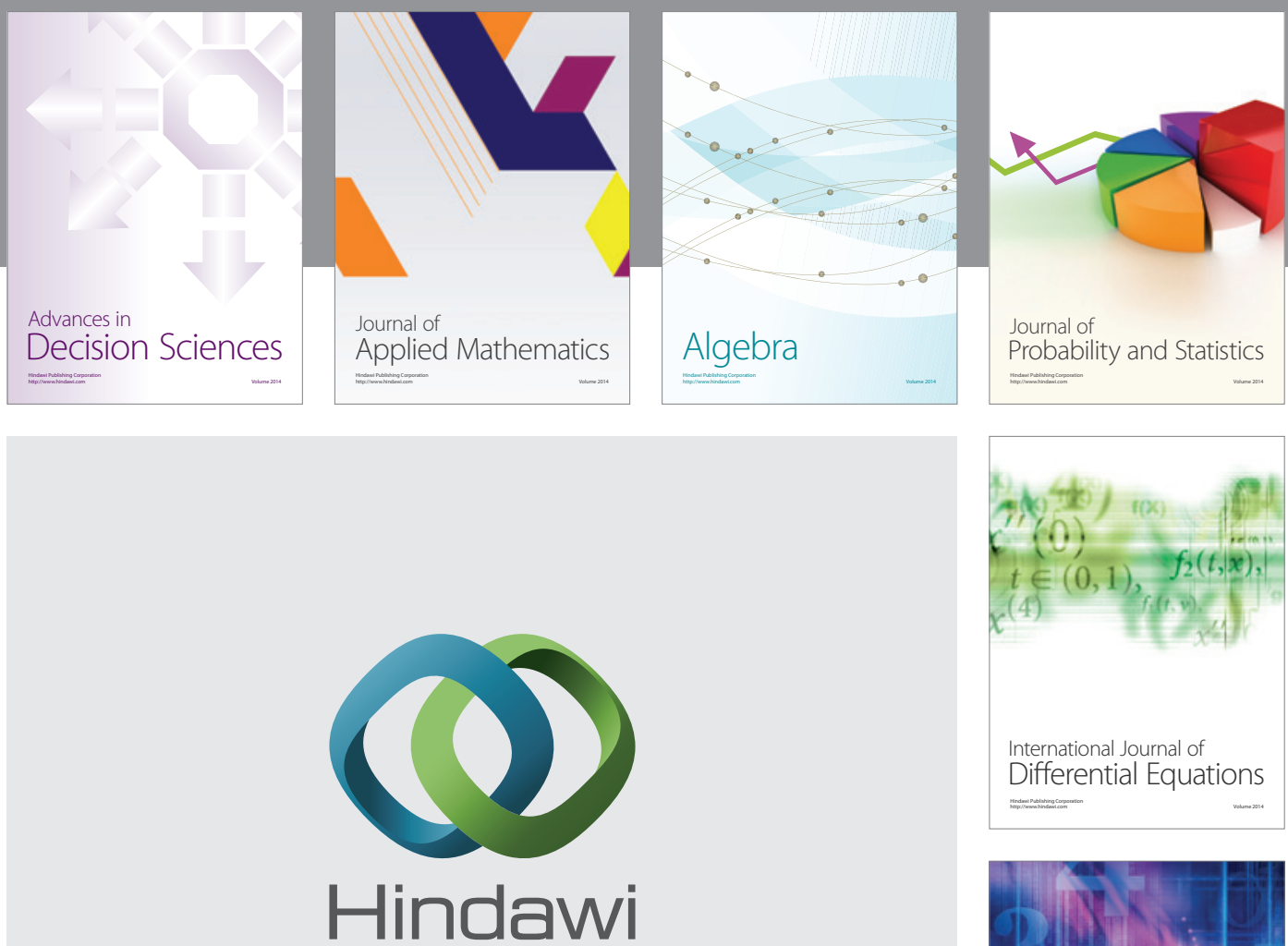

Submit your manuscripts at http://www.hindawi.com
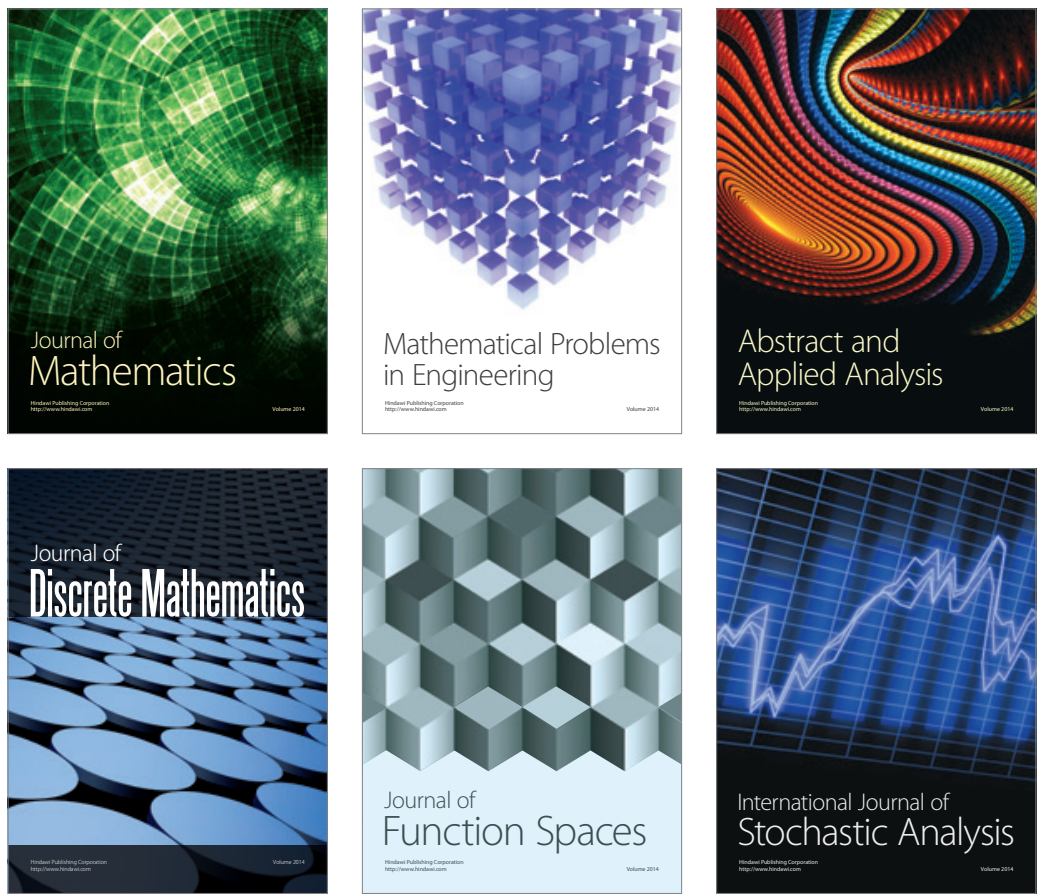

Journal of

Function Spaces

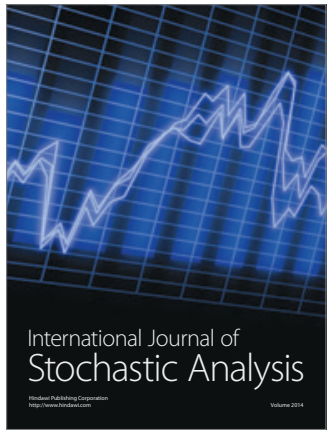

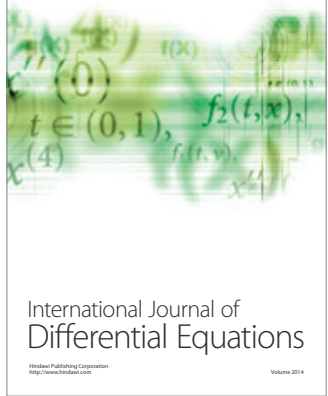
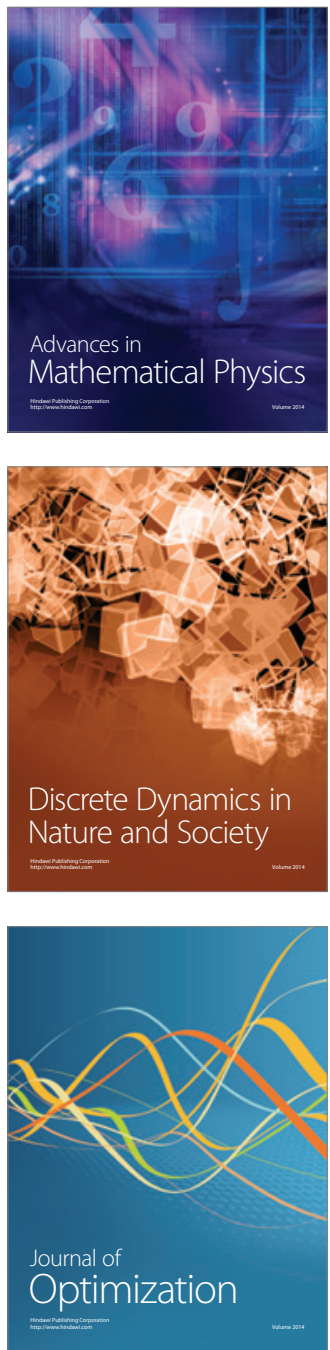